\title{
Calculating continental strength from thermal history
}

\section{from Marcia McNutt}

Sedimentary basins in continental interiors contain economically important oil, gas and coal deposits. The development of such basins has been largely controlled by the thermal history and mechanical response to sediment loading of the underlying crust and uppermost mantle (the 'continental lithosphere'). N. Kusznir and $\mathrm{G}$. Karner report on page 138 the use of rock deformation data from laboratory experiments to determine directly the mechanical properties of the lithosphere from the thermal history of a basin. In as far as the extrapolation of laboratory experiments to geological loading rates remains valid, their formulation provides a mechanism for inferring the thermal parameters that govern basin development from observations of the mechanical strength of the continental lithosphere through time.

As a first approximation, the long-term mechanical behaviour of the lithosphere resembles that of an elastic plate with strength characterized by its elastic thickness $T_{\mathrm{e}}$. Rocks above the depth $T_{\mathrm{e}}$ are strong enough to support elastically the stresses imposed by the sediment, whereas rocks below that depth deform ductilely to relax stress. The elastic thickness is primarily controlled by thermally activated creep mechanisms and hence the temperature in the lithosphere. The expectation is that a sedimentary unit deposited on hot, weak continental lithosphere will load a thin elastic plate to produce a narrow, relatively deep stratigraphic horizon. The same volume of sediment deposited on a cold, thick lithospheric plate will produce a broad, thin horizon. Therefore, stratigraphic cross-sections provide information on the mechanical strength, and by inference the thermal state, of the lithosphere during the period of basin formation.

The thermal state of the lithosphere is often summarized in terms of its thermal thickness $L$, the depth to which conduction as opposed to convection is the primary mechanism of heat transfer, and its thermal age $t$, which is the time necessary for the lithosphere to cool conductively to its present state from an initial temperature of about $1,300^{\circ} \mathrm{C}$ (the temperature maintained at its base). A sedimentary basin is thought to form after horizontal tractions stretch and thin the lithosphere (McKenzie, D. Earth planet. Sci. Lett. 40, $25 ; 1978)$. Upwelling of hotter mantle isotherms heats the lithosphere. The subsequent cooling and subsidence of the thinned lithosphere are completely described by the initial thermal age $t$, the stretching factor $\beta$, and the conductive cooling law for a slab of thickness $L$. Within the context of this thermal description of the continental lithosphere, Kusznir and Karner quantify the expected variations in mechanical strength of basin lithosphere.

The elastic thickness $T_{\mathrm{e}}$ of very old lithosphere ( $t$ more than one billion years) is most sensitive to the thickness of the conductive layer $L$. If $L$ is $125 \mathrm{~km}-$ the generally accepted value for the oceanic lithosphere (Parsons, B. E. and Sclater, J. G. J. geophys. Res. 82, 803; 1977 ) - then the greatest $T$ 2e 3 values observed for old continental lithosphere should be about $50 \mathrm{~km}$. Based on observed values of $T 2 \mathrm{e} 3$ in excess of $90 \mathrm{~km}$ for the old lithosphere beneath the Ganges and Appalachian basins, Kusznir and Karner favour a value for $L$ closer to $225 \mathrm{~km}$ for continents.

The stretching factor produces observable variations in the elastic thickness by introducing perturbations to the thermal structure. For the expected range in $\beta$, extremely stretched lithosphere will seem to have an elastic thickness more than 10 $\mathrm{km}$ thinner than modestly stretched lithosphere for sedimentary loads deposited during the first 10 million years of basin subsidence. Decay of the thermal transient gradually eliminates any $\beta$ dependence for loads deposited 100 million years later, so that one must study the deepest layers of sedimentary basins to gain insight into the initiating mechanism.

Other factors complicate the simple relationship between elastic plate thickness and thermal anomalies. For example, all rocks below the depth $T_{\mathrm{e}}$ do not relax instantaneously to relieve the stresses from sedimentary loading. Initially, the deflection of the continental lithosphere corresponds to $T_{\mathrm{e}}=L$, the full thermal thickness of the lithospheric plate. Relaxation begins at the base of the plate, rapidly at first but then asymptotically approaching $T_{\mathrm{e}}$ with time. Thermally young lithosphere ( $t=10$ million years) essentially reaches its long-term value of $T_{\mathrm{e}} \approx 10 \mathrm{~km}$ after only one million years because of rapid cooling of the plate. In older lithosphere ( $t=300$ million years), stresses at the base of the plate continue to relax, so that the effective elastic thickness of about $50 \mathrm{~km}$ decreases by a few kilometres between 1 and 10 million years. Therefore, for young loads less than 1 to 10 million years old, transient effects may cause the lithosphere to appear thicker than predicted by the steady-state theory.

The thickness of the crustal portion of the continental lithosphere is another complicating factor. The rocks in the crust, which are rich in quartz, have a lower activation energy for ductile flow than the olivine-rich rocks in the upper mantle. The lower activation energy causes ductile flow in the lower crust at fairly modest temperatures. For a given temperature structure, continental lithosphere seems weaker as the ratio of crustal to mantle portion increases. Thus two different basins both with thermal structures for $\mathbf{1 0 0}$ million-year-old lithosphere can have $T_{\mathrm{e}}$ values that differ by as much as $30 \mathrm{~km}$ if their crustal thicknesses differ by a factor of two.

Provided we can make allowance for the nonthermal parameters affecting the mechanical strength of the lithosphere, the elastic flexural signal preserved in sedimentary basins can be used to determine the thermal history which controls hydrocarbon formation. Kusznir and Karner's work identifies the variables and the magnitudes of the effects involved in such thermo-mechanical studies of sedimentary basins.

Marcia McNutt is in the Department of Earth and Planetary Sciences, Massachusetts Institute of Technology, Cambridge, Massachusetts 02139, USA.

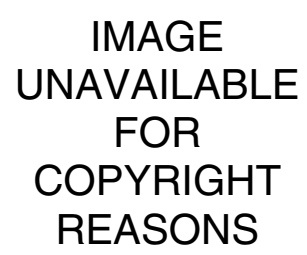

Light photomicrograph $(\times 10)$ of Volvox. Taken by Ron Oldfield of Macquarie University in Australia, this photograph won first prize in a Polaroid Instant Photomicrography Competition. 